\title{
The Mental Foramen I: Radiographic Study of the Anterior- Posterior Position and Shape in Iraqi Population
}

\author{
Foramen Mental I: Estudio Radiográfico de su Posición \\ Antero-posterior y Forma en Población Iraquí
}

Mohammad H. Al-Shayyab"; Firas Alsoleihat**; Najla S. Dar-Odeh*; Soukaina Ryalat* \& Zaid H. Baqain***

AL-SHAYYAB, M. H.; ALSOLEIHAT, F.; DAR-ODEH, N. S.; RYALAT, S. \& BAQAIN, Z. H. The mental foramen I: radiographic study of the anterior-posterior position and shape in Iraqi population. Int. J. Morphol., 33(1):149-157, 2015.

SUMMARY: Accurate information regarding the horizontal location and shape of the mental foramen can have clinical significance, such as reducing complications that may occur during maxillofacial surgical procedures involving the mental area. Geographic variations were reported in these variables. The aim was to study the horizontal position and shape of the mental foramen, as seen on panoramic radiographs of an Iraqi sample, to assess difference in these variables between sexes and age groups, and to assess symmetry of the mental foramen. 518 panoramic radiographs of a random Iraqi sample ( 257 males, 261 females, average age $=46.5$ years $)$ were evaluated with regard to the horizontal location, shape and symmetry of the mental foramina. The area between the long axes of the two mandibular premolars, and the round type were the most frequent horizontal location and shape of mental foramen, respectively. Age advancement was found to be associated with an increase in the frequency of more posterior positioning and irregular shape. The horizontal position and shape were asymmetrical in $21.6 \%$ and $31.6 \%$ of cases, respectively. The Symmetry in horizontal location and shape of mental foramina were found statistically significant between sexes $(\mathrm{P}=0.041)$, and between young and old age groups $(\mathrm{P}=0.001)$, respectively. The most common horizontal location and shape of the mental foramen on panoramic radiographs in this group are between the two premolars, and the round type, respectively. This is in consistence with the findings of previous studies on other populations. The mental foramina have usually symmetrical horizontal locations and shapes.

KEY WORDS: Mental foramen; Panoramic radiographs; Geographic variation; Iraqi population.

\section{INTRODUCTION}

The mental foramen is located on the anterolateral aspect of the buccal cortex of the body of the mandibular bone where the inferior alveolar nerve and artery, after traveling through the inferior dental canal, exit and then provide the mental and nerves and vessels. These vessels and nerves are responsible for blood supply and innervation of the lower lip, the buccal vestibule, and the gingiva mesial to the first mandibular molar (Bavitz et al., 1993; Haghanifar \& Rokouei, 2009; Williams et al., 2000). The usual horizontal (anterior-posterior) position of the mental foramen has been reported to be between the apices of the mandibular premolars in some populations (Al-Khateeb et al., 2007; Moiseiwitsch, 1998) and below the mandibular second premolar in others (Al Jasser \& Nwoku, 1998; Green, 1987; Phillips et al., 1990; Shankland, 1994; Wang et al. 1986). However, individual variation could lead to other locations ranging from the apex of the canine to the apex of the mesiobuccal root of the mandibular first molar (Fishel et al., 1976; Sweet, 1959). In the same way, the shape of the mental foramen on panoramic radiographs commonly appears as an oval or circular opening on the anteriolateral surface of the mandible. However other rare shapes have been reported in other individuals such as the irregular type (Al-Khateeb et al., 2007). It has recently been reported that these individual variations are present between populations of different geographies (Ari et al., 2005).

Accurate information regarding the horizontal location and shape of the mental canal and its foramen can have very important clinical significance. Accurately locating the horizontal position of the mental foramen would help in achieving successful local anesthesia to the

\footnotetext{
* Department of Oral and Maxillofacial Surgery, Oral Medicine and Periodontology, Faculty of Dentistry, The University of Jordan, Amman, Jordan. ** Department of Conservative Dentistry, Faculty of Dentistry, The University of Jordan, Amman, Jordan.

**** Dean, Department of Oral and Maxillofacial Surgery, Oral Medicine and Periodontology, Faculty of Dentistry, The University of Jordan, Amman, Jordan.
} 
terminal branches of the inferior alveolar nerve. Additionally, it may reduce the rate of parasthesia or anesthesia and hemorrhage in the mental region, the lower lip and the gingiva from the mental foramen to the midline of the ipsilateral side. These complications may occur as a result of traumatizing the mental bundle during many oral surgical procedures such as osteotomy, implant surgery and any other invasive surgical procedure involving the mental region (Phillips et al., 1990). The shape and other anatomical characteristics could also be used in evaluating some morphological and paleoanthropologic features of the human mandible and of the facial skeleton in different populations (Hasan, 2011).

The horizontal location and shape of mental foramen have been studied in different populations by clinical radiographs (Al Jasser \& Nwoku, 1996; al-Khateeb et al., 1994; Laster et al., 2005; Olasoji et al., 2004; Phillips et al., 1992a, 1992b; Yosue \& Brooks, 1989a, 1989b) or by examining collections of dried skulls (Agthong et al., 2005; Berge \& Bergman, 2001; Cutright et al., 2003; Igbigbi \& Lebona, 2005; Mbajiorgu et al., 1998; Mwaniki \& Hassanali, 1992; Ngeow \& Yuzawati, 2003; Phillips et al., 1992a, 1992b; Sawyer et al., 1998; Souaga et al., 2004). Since the Gulf war in 1991, a dramatic increase of Iraqi population in Jordan, especially in the capital city Amman, has been noticed by the Jordanian immigration authority which reported more than half million of them entering and leaving Jordan since 1990 up to March 2007 (Wikipedia). Thus, Iraqi patients could form a considerable percentage of patients in any dental practice in Jordan given that the total population of Jordan was estimated to be about 6.5 million in 2012, of those 2.2 million are in Amman. The aim of the present study was to study the panoramic horizontal position and shape of the mental foramen in Iraqis, and to compare our findings with international values; it has been investigated for the first time in this population.

\section{MATERIAL AND METHOD}

Six hundred panoramic radiographs were randomly selected from over-many-year records of Iraqi patients referred to and treated in a referral dental care center in Iraq (Martyr Adnan Kair Allah Teaching Hospital for Specialized Surgeries) and in the Jordan University Hospital in Amman, the capital city of Jordan where most Iraqis in Jordan are present. The radiographic system and criteria used and exposure time for all chosen radiographs were different between the two canters. However, their viewing qualities were regarded to be optimal and deemed of a good diagnostic quality. This was because the manufacturer's operation manuals were followed. The 518 panoramic radiographs were the final number of radiographs included in the present study after excluding 82 radiographs due to varies reasons:

1. Patients aged less than 18 years.

2. The presence of a radiolucent lesion or periodontal lesions, or a missing or an impacted tooth, or a crowding and spacing anywhere in the area extending from the lower right first molar to the lower left first molar.

3. Patient with history of orthodontic treatment of lower arch crowding and spacing.

4. Poor film quality.

A data collection form was designed and used to record the anterior-posterior position and shape of mental foramen on radiographs which are already scanned on the computer. This was done by two observers (maxillofacial senior residents) and in standard viewing conditions such as adjusting the brightness and contrast of the computer's screen in a dark room to make radiographs appear clearer. Some differences was found between the two observers and resolved by agreement with the opinion of the maxillofacial radiology consultant in Jordan University Hospital.

Anterior-posterior position of the mental foramen. A longitudinal axis of each mandibular premolar was drawn on both sides utilizing the drawing ruler of the software. Using the same definitions found in the literature (AlKhateeb et al., 2007; Haghanifar \& Rokouei, 2009), the anterior-posterior position of each mental foramen was then recorded in relation to the longitudinal axis of the nearest tooth as follows:

Position 1: Anterior to the first premolar Position 2: In line with the first premolar Position 3: Between the first and second premolars Position 4: In line with the second premolar

Position 5: Between the second premolar and first molar Position 6: In line with the first molar

Shape of the mental foramen. The shape of the foramen was recorded as round or oval or irregular. This was achieved by using the drawing ruler of the software to outline the external circumference of each mental foramen.

Statistical analysis. SPSS version 17.0 (SPSS Inc., Chicago, IL, USA) statistical software program was used to undertake the statistical analysis. Frequency distributions and cross tabulation were obtained, and chi-square test was used to perform analyses of the mental foramina's anterior-posterior position, shape and symmetry according to patients' age and sex. P-value of $<0.05$ was considered as significant. 


\section{RESULTS}

The included 518 panoramic radiographs were analyzed on both sides, and were 257 for males and 261 for females with a 1:1.02 female-to-male ratio. The average age of selected subjects was 46.5 with standard deviation of 13.8 years, ranging from 18 to 79 years. Table I and II detail the horizontal position and the shape of the mental foramen.

Horizontal (Anterior-posterior) position. The most common horizontal position for the mental foramen in this Iraqi sample was in the area between the long axes of mandibular premolars (48.6\%) (Fig. 1: left side), with the position in line with the long axis of second mandibular premolar being the second most common (43.7\%) (Fig. 2). A position for the mental foramen anterior to the first premolar was not observed. The most frequent horizontal position was noticed to be not different between right and left sides (Table I), and among males and females (Table II). Age advancement was noticed to positionthe mental foramen in more posterior locations (Fig. 3).
In 406 cases ( $78.4 \%$ ), the position of mental foramina anterioposteriorly were symmetrical (Fig. 2) and the remainder 112 cases (21.6\%) were asymmetrical (Fig. 4). In the present sample, males $(82.1 \%)$ and young age group (11-40 years) (80.6\%) recorded more symmetrical position for the mental foramen than females $(74.7 \%)$ and old ages (>40 years) (76.9\%), respectively. However, only the malefemale difference in symmetry of the horizontal location of mental foramen was found to be statistically significant $(\mathrm{P}=0.041)$ (Table III).

The shape of mental foramen. The most common (51\%) shape of the mental foramen in this Iraqi sample was round type (Fig. 1), with the oval one being the second most common (41\%) (Fig. 2). This most frequent shape was not different between right and left sides (Table I), and among males and females (Table II). Age advancement was noticed to provide more irregular shape of the mental foramen (Fig. 5).

Table I. Distribution of the horizontal position and shape of mental foramen on both sides by sex ( $\mathrm{n}=1,036$ sides).

\begin{tabular}{|c|c|c|c|c|c|c|c|c|c|c|c|}
\hline \multirow{3}{*}{\multicolumn{2}{|c|}{ Radiographic features of the }} & \multicolumn{8}{|c|}{ Sex } & \multirow{3}{*}{ Total } & \multirow{3}{*}{$\%$} \\
\hline & & \multicolumn{4}{|c|}{ Male } & \multicolumn{4}{|c|}{ Female } & & \\
\hline & & Right & $\%$ & Left & $\%$ & Right & $\%$ & Left & $\%$ & & \\
\hline \multirow{7}{*}{$\begin{array}{l}\text { AP } \\
\text { position }\end{array}$} & Anterior to LP1 & 0 & 0.0 & 0 & 0.0 & 0 & 0.0 & 0 & 0.0 & 0 & 0.0 \\
\hline & In line with LP1 & 4 & 1.6 & 7 & 2.7 & 6 & 2.3 & 10 & 3.8 & 27 & 2.6 \\
\hline & Between LP1 and LP2 & 126 & 49.0 & 113 & 44.0 & 128 & 49.0 & 137 & 52.5 & 504 & 48.6 \\
\hline & In line with LP2 & 111 & 43.2 & 119 & 46.3 & 116 & 44.4 & 107 & 41.0 & 453 & 43.7 \\
\hline & Between LP2 and LM1 & 15 & 5.8 & 17 & 6.6 & 11 & 4.2 & 7 & 2.7 & 50 & 4.9 \\
\hline & In line with LM1 & 1 & 0.4 & 1 & 0.4 & 0 & 0.0 & 0 & 0.0 & 2 & 0.2 \\
\hline & Total & 257 & 100.0 & 257 & 100.0 & 261 & 100.0 & 261 & 100.0 & 1036 & 100.0 \\
\hline \multirow[t]{4}{*}{ Shape } & Round & 144 & 56.0 & 119 & 46.3 & 134 & 51.3 & 134 & 51.3 & 531 & 51.0 \\
\hline & Oval & 87 & 33.9 & 114 & 44.4 & 114 & 43.7 & 110 & 42.1 & 425 & 41.0 \\
\hline & Irregular & 26 & 10.1 & 24 & 9.3 & 13 & 5.0 & 17 & 6.5 & 80 & 8.0 \\
\hline & Total & 257 & 100.0 & 257 & 100.0 & 261 & 100.0 & 261 & 100.0 & 1036 & 100.0 \\
\hline
\end{tabular}

Table II. Frequency of the horizontal position and shape of mental foramen (by sex) as seen in the present study ( $\mathrm{n}=1,036$ sides).

\begin{tabular}{llcccccc}
\multicolumn{2}{c}{ Radiographic features of the foramen } & Male & \% & Female & \% & Total & \multirow{2}{*}{} \\
\hline AP & Anterior to LP1 & 0 & 0.0 & 0 & 0.0 & 0 & 0.0 \\
position & In line with LP1 & 11 & 2.2 & 16 & 3.1 & 27 & 2.6 \\
& Between LP1 and LP2 & 239 & 46.5 & 265 & 50.3 & 504 & 48.6 \\
& In line with LP2 & 230 & 44.7 & 223 & 42.7 & 453 & 43.7 \\
& Between LP2 and LM1 & 32 & 6.2 & 18 & 3.5 & 50 & 4.9 \\
& In line with LM1 & 2 & 0.4 & 0 & 0.0 & 2 & 0.2 \\
\multirow{5}{*}{ Shape } & Total & 514 & 100.0 & 522 & 100.0 & 1036 & 100.0 \\
& Round & 263 & 51.0 & 268 & 51.0 & 531 & 51.0 \\
& Oval & 201 & 39.0 & 224 & 43.0 & 425 & 41.0 \\
& Irregular & 50 & 10.0 & 30 & 6.0 & 80 & 8.0 \\
& Total & 514 & 100.0 & 522 & 100.0 & 1036 & 100.0 \\
\hline
\end{tabular}

$\mathrm{AP}=$ anterior-posterior; $\mathrm{LP} 1=$ lower first premolar; $\mathrm{LP} 2=$ lower second premolar; $\mathrm{LM} 1=$ lower first molar 
Table III. The horizontal position and shape of mental foramen by sex and symmetry ( $\mathrm{n}=518$ cases).

\begin{tabular}{|c|c|c|c|c|c|c|c|}
\hline & & & Symmetrical & $\%$ & Asymmetrical & $\%$ & $\mathbf{P}$ \\
\hline \multirow{6}{*}{$\begin{array}{l}\text { Sex } \\
\text { difference }\end{array}$} & \multirow{3}{*}{$\begin{array}{l}\text { Anterior-posterior } \\
\text { position }\end{array}$} & Male & 211 & 52.0 & 46 & 41.1 & \multirow[t]{3}{*}{$0.041 *$} \\
\hline & & Female & 195 & 48.0 & 66 & 58.9 & \\
\hline & & Total & 406 & 100.0 & 112 & 100.0 & \\
\hline & \multirow[t]{3}{*}{ Shape } & Male & 176 & 49.0 & 81 & 50.9 & \multirow[t]{3}{*}{0.687} \\
\hline & & Female & 183 & 51.0 & 78 & 49.1 & \\
\hline & & Total & 359 & 100.0 & 159 & 100.0 & \\
\hline \multirow{6}{*}{$\begin{array}{l}\text { Age } \\
\text { groups }\end{array}$} & \multirow{3}{*}{$\begin{array}{l}\text { Anterior-posterior } \\
\text { position }\end{array}$} & $11-40$ & 170 & 41.9 & 41 & 36.6 & \multirow[t]{3}{*}{0.315} \\
\hline & & $>40$ & 236 & 58.1 & 71 & 63.4 & \\
\hline & & Total & 406 & 100.0 & 112 & 100.0 & \\
\hline & \multirow[t]{3}{*}{ Shape } & $11-40$ & 129 & 35.9 & 82 & 51.6 & \multirow[t]{3}{*}{$0.001 *$} \\
\hline & & $>40$ & 230 & 64.1 & 77 & 48.4 & \\
\hline & & Total & 359 & 100.0 & 159 & 100.0 & \\
\hline
\end{tabular}

$\mathrm{P}=\mathrm{P}$ value of Chi-square test; $*$ Statistically significant at the 0.05 probability level.

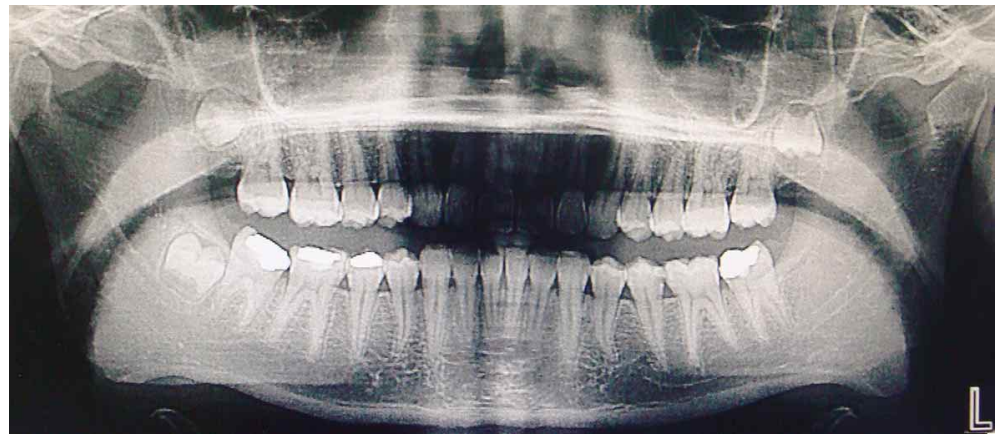

Fig. 1. A panoramic radiograph showing asymmetrical anterior-posterior location and symmetrical shape of mental foramina.

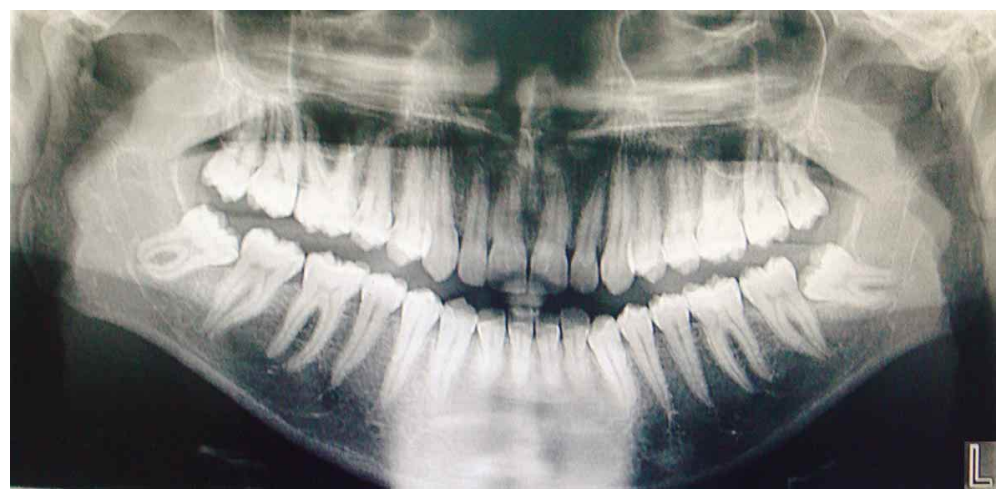

Fig. 2. A panoramic radiograph showing the mental foramina symmetrically shaped, as an oval type, and located at the apical level of mandibular second premolar teeth.

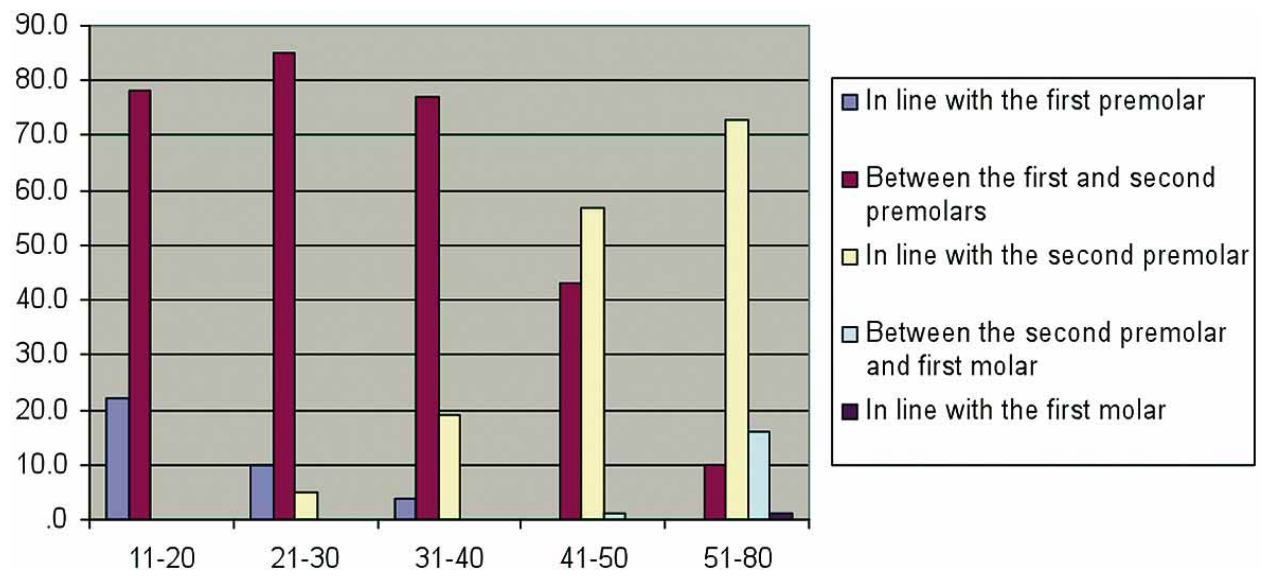

Fig. 3. A clustered graph showing the effect of advancing age on the anterior-posterior location of the mental foramen $(n=1,036$ cases $)$. 


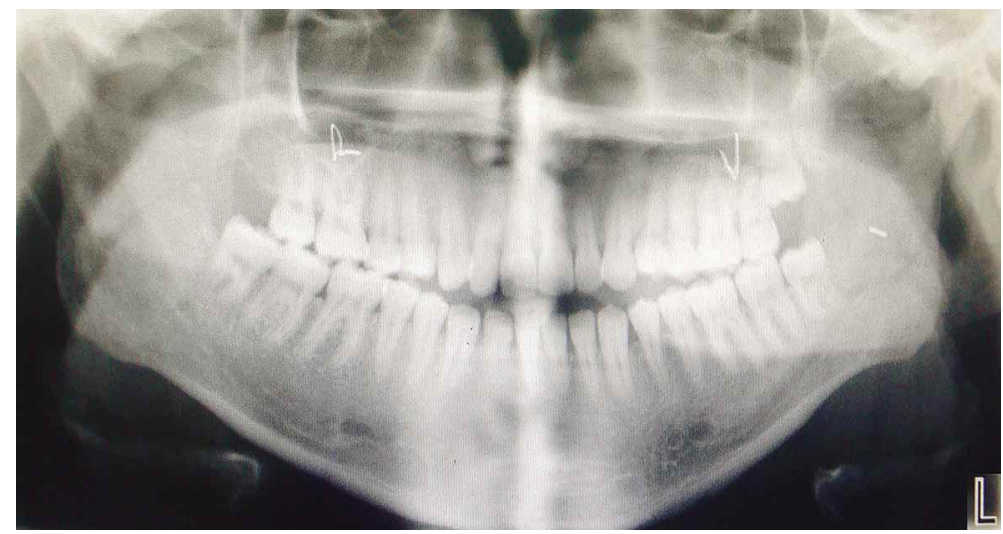

Fig. 4. A panoramic radiograph showing asymmetric anterior-posterior position and shape of mental foramina.

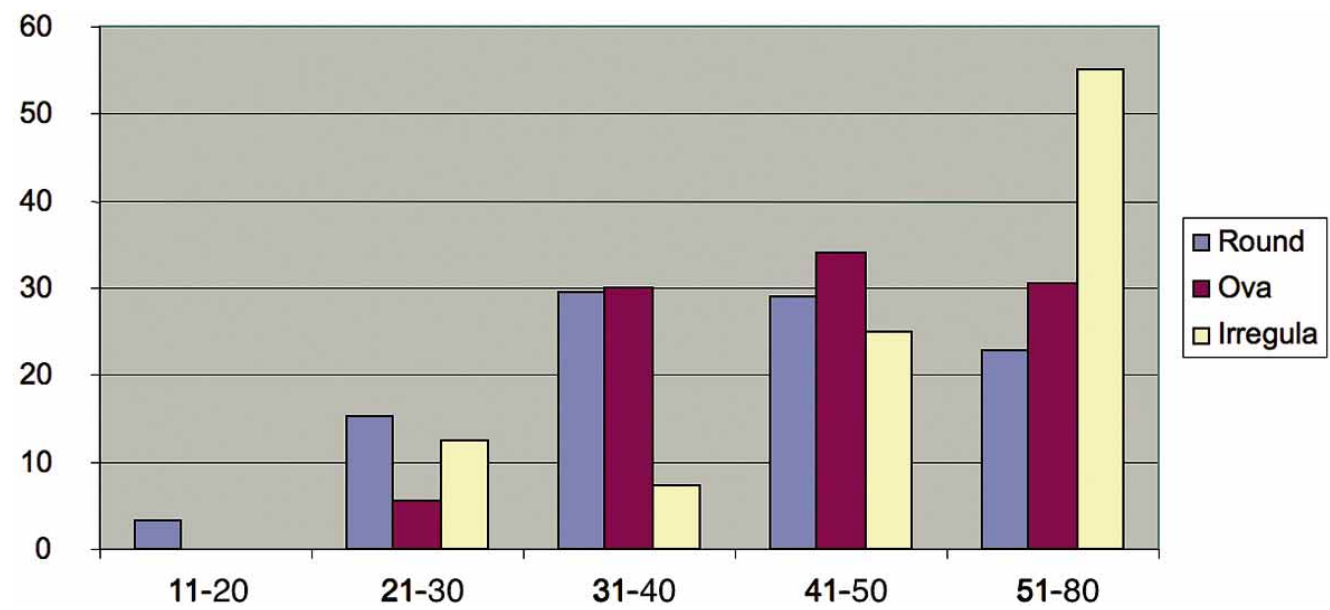

Fig. 5. A clustered graph showing the effect of advancing age on the shape of the mental foramen $(\mathrm{n}=1,036$ cases).

\section{DISCUSSION}

Knowledge concerning the exact anterior-posterior location and shape of the mental foramen is of great clinical importance. It would lead to an accurate local anesthetic technique needed in many dental procedures and would protect the mental neurovascular bundle in different oral surgical procedures. Additionally, good interpretation of anatomical landmarks in oral pathology and forensics can be aided (Neo, 1989). For all of the above mentioned reasons, the horizontal location and other characteristics of the mental foramen have been studied utilizing panoramic radiographs or dry skulls. Although studies reported a strong correlation and insignificant differences between measurements using comparative studies on dry skulls and those using radiographs (Al Jasser \& Nwoku, 1998; Phillips et al., 1990; Wang et al.; Yosue \& Brooks, 1989a), a cautious use of panoramic radiographs in reporting absolute measurements or relative comparisons has been advised (Laster et al., 2005).
In this study, the anterior posterior position and shape of the mental foramen in a selected Iraqi population were studied using panoramic radiographs rather than other plane films such as periapical radiographs which would not provide the wide field of mandible view. Consequently, more accurate interpretation of shape and location of the mental foramen in both the horizontal and vertical dimensions are allowed by using panoramic radiographs (Yosue \& Brooks, 1989b; Phillips et al., 1992a, 1992b). Similarly, our exclusion criteria aimed to avoid any factor that may affect accurate determination of the horizontal location or shape of the mental foramen such as periodontal lesions or history of orthodontic treatment which could lead to tooth migration. Poor film quality could also provide inaccurate or distorted shape of the foramen. In the same way, only patients over the age of 18 years were included because we needed patients with completed skeletal growth. 
Studies reported in the literature concerning the anterior-posterior localization of the mental foramen have been used in two different methods namely by relating the foramen to adjacent teeth or to the mandibular body. Relating the mental foramen position to the teeth is more popular in all over the world (Al Jasser \& Nwoku, 1998; Aktekin et al., 2003; Cutright et al.; Green; Matheson et al., 1986; Moiseiwitsch; Mwaniki \& Hassanali; Ngeow \& Yuzawati; Olasoji et al.; Phillips et al., 1990, 1992a, 1992b) and more convenient clinically (Green) but may be influenced by congenital or environmental factors such as race, diet, and age which have their detrimental effects on teeth alignment (i.e. malocclusion) or size (i.e. mesiodistal width). The other method is more reliable as it relates the foramen to specific points and ratios on the mandible (Apinhasmit et al., 2006; Laster et al.; Oguz \& Bozkir, 2002). However, this later method is more time-consuming which is not convenient for busy clinicians.

Different anterior-posterior positions and shapes of mental foramen have recently been reported to be existed between population of different or even of the same geography (Ari et al.; Igbigbi \& Lebona; Mbajiorgu et al.; Souaga et al.). Additionally, positions of the mental foramen other than the two most common described above and consequently variable characteristics were attributed to the possible lag in developmental changes in its location during postnatal life. This attribution was drawn because the very early position of the mental foramen was found to be in the alveolar bone between the primary canine and first molar (Kjaer, 1989).

In our series of 518 panoramic radiographs the anterior-posterior location of the mental foramen was most commonly (48.6\%) in the area between the long axes of first and second mandibular premolars, with $(43.7 \%)$ the position in line with the long axis of second mandibular premolar being the second most common; thus $92.3 \%$ of foramina lie at either these two positions. Therefore, about $92 \%$ success rate of the mental or incisive nerve block, compared to $95 \%$ reported on a sample of northern Jordanians (Al-Khateeb et al., 2007), could be expected if the needle insertion point is placed at either of or between these two points. Studies on a North American white population (Moiseiwitsch), Northern Nigerian adults (Fishel et al.; Olasoji et al.), Iranian adults (Haghanifar \& Rokouei), northern Jordanian adults (AlKhateeb et al., 2007) and most Caucasian populations from different countries (Cutright et al.; Laster et al.; Moiseiwitsch; Phillips et al., 1990, 1992a, 1992b) reported the area between the two premolars as the most common location of the mental foramen. These findings agree with our results but disagree with studies done on other populations such as Saudis, Malays, Asian Indians, Kenyan
Africans, Saudis, and on other Sino-American and SubSaharan African populations, from different countries, which reported more posterior positions of the mental foramen (Agthong et al.; Aktekin et al.; Al Jasser \& Nwoku; Apinhasmit et al.; Cutright et al.; Igbigbi \& Lebona; Mbajiorgu et al.; Mwaniki \& Hassanali; Ngeow \& Yuzawati; Oguz \& Bozkir; Wang et al.) or specifically in line with the second premolar tooth (Al Jasser \& Nwoku, 1996, 1998; Berkovitz et al., 2002; Liebgott, 2001; Mwaniki \& Hassanali; Ngeow \& Yuzawati; Phillips et al., 1992a, 1992b; Shankland, 1994; White \& Pharoah, 2004; Woelfel \& Scheid, 2002). On the other hand, some studies have reported that both locations are common (Malamed, 2004; Williams et al.).

In this study, we have found no case with a horizontal position of the mental foramen anterior to the first premolar. This agrees with previous studies in some regional countries such as Jordan (Al-Khateeb et al., 2007), Saudi Arabia (al-Khateeb et al., 1994) and Iran (Haghanifar \& Rokouei). Some of these previous studies (al-Khateeb et al., 1994, 2007) reported that in males the most frequent anterior- posterior position of the mental foramen was between the first and second mandibular premolar teeth, and in females along the line of the second mandibular premolar with no reference to the differences between right and left sides, as the right and left sides were not considered separately. Other previous studies (Al Jasser \& Nwoku; Haghanifar \& Rokouei) reported that on the right side, the commonest position of the mental foramen was between the first and second premolars, and on the left side it was in line with the second premolar. Additionally, they (Haghanifar \& Rokouei) reported that the position in line with the second premolar was the most common one among males and the position between the first and second premolars was the most common one among females. However, these previous studies disagree with our findings which have indicated that the most frequent anterior-posterior position was not different between right and left sides, and among males and females. This might indicate geography related differences in the degree of bilateralism and sexual dimorphism in the horizontal location of the mental foramen (Ari et al.).

Regarding the effect of age on the anterior-posterior location of the mental foramen, Age advancement was noticed to position the mental foramen in more posterior locations. Our later finding also agrees with those of previous studies (Agthong et al.; Al-Khateeb et al., 2007) which attributed this posterior shift in positioning to the anterior tooth drift that occurs due to the expected age-related attrition of interproximal surfaces of teeth.

We have found that the position of the mental foramen was asymmetrical anteroposteriorly in about one fifth 
of the cases. This figure of frequency of asymmetry is higher than that reported in Saudi Arabia (Al Jasser \& Nwoku, 1998) and North America (Moiseiwitsch) but lower than that reported in Jordan (Al-Khateeb et al., 2007) where sex and age differences, and the statistical significance of these differences were not considered. In this study, difference in the rate of symmetry in the anterior-posterior location of mental foramen was found to be statistically significant differences between males and females. This disagrees with previous studies on other populations (Haghanifar \& Rokouei) where no statistically significant difference was found between males and females in symmetry of the horizontal location of mental foramen.

In the present study, we observed a round-shaped mental foramen in $51 \%$ of the cases and an oval-shaped foramen in $41 \%$. These figures are very close to those reported in some regional countries (Al-Khateeb et al., 2007) and agree with results reported on some populations in other parts of the world (Singh \& Srivastav, 2010). However, our findings disagree with studies on other populations (Agarwal \& Gupta, 2011; Gershenson et al., 1986; Igbigbi \& Lebona; Mbajiorgu et al.; Probodra \& Nanayakkara, 2006; Souaga et al.), which showed that the most frequent shape was oval. Additionally, we have found that this most frequent shape was not different between right and left sides, and among males and females. However, age advancement was noticed to provide an increase in the frequency of more irregular shape of the mental foramen. These later results found in this study concerning side, sex and age differences were not investigated in most of the previous studies on various populations (Al Jasser \& Nwoku, 1998; al-Khateeb et al., 1994, 2007; Mbajiorgu et al.; Oguz \& Bozkir; Olasoji et al.; Phillips et al., 1990, 1992a; Yosue \& Brooks, 1989a). However, some of these studies (Al-Khateeb et al., 2007) only showed that the most frequent shape of the mental foramen (round) was more common in females than males which disagree with our findings. On this regard, it is important to mention that the remarkable portion of round-shaped mental foramen was attributed by some (Schulze et al., 2000) to possible technical problems that could occur during taking panoramic radiographs such as magnification and positioning inaccuracies. Alternatively, the most common shape of the mental foramen might be geography-related (Ari et al.).

We have found that the shape of the mental foramen was asymmetrical in about one third of the cases. This figure of frequency of asymmetry is higher than that reported in Saudi Arabia (Al Jasser \& Nwoku, 1998) and Jordan (AlKhateeb et al., 2007) where age related differences and their statistical significance were not investigated. However, they only reported higher frequency of asymmetry in the shape of mental foramen in Jordanian males than females (Al-
Khateeb et al., 2007). In this study, statistically significant difference was found between old and young age groups in the frequency of symmetry of the shape of mental foramen, in favor of the older group.

Generally, the developmental and functional facts are likely to explain the variability and asymmetry in the horizontal position and shape of mental foramen. The mandible from developmental and functional point of views consists of several skeletal subunits; a primary neural subunit and secondary functional subunits (Sperber, 2001). Regarding the asymmetry of the mental foramen position, it is attributed to different functional secondary subunits such as the alveolar, coronoid, angular, condylar process, and chin. These secondary functional subunits are attached to the nearly symmetric primary neural subunit which is a representation of the bone surrounding the mandibular nerve or the primitive mandible. This primitive mandible is formed in the first branchial arch as the first osteogenic center of the mandibular body that arises lateral to the Meckel's cartilage and to the mandibular nerve, and rapidly forms a groove that surrounds the nerve (Captier et al., 2006).

Finally, although research results and, functional and developmental facts may explain the variability and asymmetry in the anterior-posterior position and shape of mental foramen, the reason of this variability and asymmetry between people of different races, geographies, ages and sexes has probably not clearly explained yet. Additionally, the study is not without limitations. It was a cross-sectional, epidemiologic retrospective study, and we selected only one area in Iraq due to limitation of time, funds and communication with Iraqi universities and hospitals. The small sample size was an additional limitation. Therefore, we feel that broad generalizations of the findings are not possible, and a further study incorporating a nationally representative sample is needed to confirm the results of the present study.

In conclusion, the most common horizontal location and shape of the mental foramen on panoramic radiographs in this group of Iraqis are between the two premolars, and round type respectively. This is consistent with the results of previous studies in other populations. The mental foramina, in the present Iraqi sample, have usually symmetrical horizontal location and shapes on both sides of the mandible.

ACKNOWLEDGEMENTS. We would like to thank Dr. Abeer Hadidi, the maxillofacial radiology consultant in Jordan University Hospital for helping us in the observation of the panoramic radiographs. 
AL-SHAYYAB, M. H.; ALSOLEIHAT, F.; DAR-ODEH, N. S.; RYALAT, S. \& BAQAIN, Z. H. Foramen mental I: estudio radiográfico de su posición antero-posterior y forma en población Iraquí. Int. J. Morphol., 33(1):149-157, 2015.

RESUMEN: Información precisa sobre la ubicación horizontal y forma del foramen mental puede tener importancia clínica en la reducción de complicaciones durante procedimientos quirúrgicos maxilofaciales que involucran el área mental. Fueron reportadas variaciones geográficas en relación a estas variables. El objetivo fue estudiar la posición horizontal y forma del foramen mental, a partir de 518 radiografías panorámicas de una muestra aleatoria en sujetos de Irak (257 varones, 261 mujeres; edad media= 46,5 años), quienes fueron evaluados con respecto a la posición horizontal, forma y la simetría de los forámenes mentales. En individuos de edad avanzada se encontró una asociación con un aumento en la frecuencia de un posicionamiento posterior y con forma irregular. La posición horizontal y forma del foramen fueron asimétricos en 21,6\% y 31,6\% de los casos, respectivamente. La diferencia hallada en relación a la simetría en posición horizontal y forma de los forámenes mentales fue estadísticamente significativa entre sexos $(\mathrm{p}=0,041)$, y entre los grupos de edad jóvenes y mayores $(\mathrm{P}=0,001)$, respectivamente. Se encontró con mayor frecuencia la posición horizontal entre los ejes longitudinales de los dos premolares mandibulares, y la forma circular, en relación a la posición antero-posterior y forma del foramen, respectivamente. Estos fueron resultados similares a estudios anteriores sobre otras poblaciones. Los forámenes mentales son simétricos, respecto a su ubicación horizontal y su forma.

PALABRAS CLAVE: Foramen mental; Radiografías panorámicas; Variación geográfica; Población Iraquí.

\section{REFERENCES}

Agarwal, D. R. \& Gupta, S. B. Morphometric analysis of mental foramen in human mandible of south Gugarat. People's J. Sci. Res., 4:15-8, 2011.

Agthong, S.; Huanmanop, T. \& Chentanez, V. Anatomical variations of the supraorbital, infraorbital, and mental foramina related to gender and side. J. Oral Maxillofac. Surg., 63(6):800-4, 2005.

Aktekin, M.; Celik, H. M.; Celik, H. H.; Aldur, M. M. \& Aksit, M. D. Studies on the location of the mental foramen in Turkish mandibles. Morphologie, 87(277):17-9, 2003.

Al Jasser, N. M. \& Nwoku, A. L. Radiographic study of the mental foramen in Saudi females. Saudi Med. J., 17:471-4, 1996.

al Jasser, N. M. \& Nwoku, A. L. Radiographic study of the mental foramen in a selected Saudi population. Dentomaxillofac. Radiol., 27(6):341-3, 1998.

al-Khateeb, T. L.; Odukoya, O. \& el-Hadidy, M. A. Panoramic radiographic study of mental foramen locations in Saudi Arabians. Afr. Dent. J., 8:16-9, 1994.

Al-Khateeb, T.; Al-Hadi Hamasha, A. \& Ababneh, K. T. Position of the mental foramen in a northern regional Jordanian population. Surg. Radiol. Anat., 29(3):231-7, 2007.

Apinhasmit, W.; Methathrathip, D.; Chompoopong, S. \& Sangvichien, S. Mental foramen in Thais: an anatomical variation related to gender and side. Surg. Radiol. Anat., 28(5):529-33, 2006.

Ari, I.; Kafa, I. M.; Basar, Z. \& Kurt, M. A. The localization and anthropometry of mental foramen on late Byzantine mandibles. Coll. Antropol., 29(1):233-6, 2005.

Bavitz, J. B.; Harn, S. D.; Hansen, C. A. \& Lang, M. An anatomical study of mental neurovascular bundle-implant relationships. Int. J. Oral Maxillofac. Implants, 8(5):563-73, 1993.
Berge, J. K. \& Bergman, R. A. Variations in size and in symmetry of foramina of the human skull. Clin. Anat., 14(6):406-13, 2001.

Berkovitz, B. K. B.; Holland, G. R. \& Moxham, B. J. Dento-osseous structures. Oral Anatomy, Histology and Embryology. 3rd ed. London, Mosby, 2002.

Captier, G.; Lethuilier, J.; Oussaid, M.; Canovas, F. \& Bonnel, F. Neural symmetry and functional asymmetry of the mandible. Surg. Radiol. Anat., 28(4):379-86, 2006.

Cutright, B.; Quillopa, N. \& Schubert, W. An anthropometric analysis of the key foramina for maxillofacial surgery. J. Oral Maxillofac. Surg., 61(3):354-7, 2003.

Fishel, D.; Buchner, A.; Hershkowith, A. \& Kaffe, I. Roentgenologic study of the mental foramen. Oral Surg. Oral Med. Oral Pathol., 41(5):682-6, 1976.

Gershenson, A.; Nathan, H. \& Luchansky, E. Mental foramen and mental nerve: changes with age. Acta Anat. (Basel), 126(1):216, 1986.

Green, R. M. The position of the mental foramen: a comparison between the southern (Hong Kong) Chinese and other ethnic and racial groups. Oral Surg. Oral Med. Oral Pathol., 63(3):28790, 1987.

Haghanifar, S. \& Rokouei, M. Radiographic evaluation of the mental foramen in a selected Iranian population. Indian J. Dent. Res., 20(2):150-2, 2009.

Hasan, T. Characteristics of the mental foramen in different populations. Internet J. Biol. Anthropol., 4(2), 2011. Available in: https://ispub.com/IJBA/4/2/6914

Igbigbi, P. S. \& Lebona, S. The position and dimensions of the mental foramen in adult Malawian mandibles. West Afr. J. Med., 24(3):184-9, 2005. 
Kjaer, I. Formation and early prenatal location of the human mental foramen. Scand. J. Dent. Res., 97(1):1-7, 1989.

Laster, W. S.; Ludlow, J. B.; Bailey, L. J. \& Hershey, H. G. Accuracy of measurements of mandibular anatomy and prediction of asymmetry in panoramic radiographic images. Dentomaxillofac. Radiol., 34(6):343-9, 2005.

Liebgott, B. The Anatomical Basis of Dentistry. 2nd ed. St. Louis, Mosby, 2001.

Malamed, S. F. Handbook of Local Anesthesia. 5th ed. St. Louis, Mosby, 2004.

Matheson, B. R.; Blanton, P. L.; Rivera-Hidalgo, F.; Rees, T. D.; Bradley, R. E. \& Dill, R. Utilization of an intraoral landmark to localize the mental foramen. J. Dent. Res. , 63A:278-80, 1986.

Mbajiorgu, E. F.; Mawera, G.; Asala, S. A. \& Zivanovic, S. Position of the mental foramen in adult black Zimbabwean mandibles: a clinical anatomical study. Cent. Afr. J. Med., 44(2):24-30, 1998.

Moiseiwitsch, J. R. Position of the mental foramen in a North American, white population. Oral Surg. Oral Med. Oral Pathol. Oral Radiol. Endod., 85(4):457-60, 1998.

Mwaniki, D. L. \& Hassanali, J. The position of mandibular and mental foramina in Kenyan African mandibles. East Afr. Med. J., 69(4):210-3, 1992.

Neo, J. Position of the mental foramen in Singaporean Malays and Indians. Anesth. Prog., 36(6):276-8, 1989.

Ngeow, W. C. \& Yuzawati, Y. The location of the mental foramen in a selected Malay population. J. Oral Sci., 45(3):171-5, 2003.

Oguz, O. \& Bozkir, M. G. Evaluation of location of mandibular and mental foramina in dry, young, adult human male, dentulous mandibles. West Indian Med. J., 51(1):14-6, 2002.

Olasoji, H. O.; Tahir, A.; Ekanem, A. U. \& Abubakar, A. A. Radiographic and anatomic locations of mental foramen in northern Nigerian adults. Niger. Postgrad. Med. J., 11(3):230-3, 2004.

Phillips, J. L.; Weller, R. N. \& Kulid, J. C. The mental foramen: 1. Size, orientation, and positional relationship to the mandibular second premolar. J. Endod., 16(5):221-3, 1990

Phillips, J. L.; Weller, R. N. \& Kulild, J. C. The mental foramen: 2. Radiographic position in relation to the mandibular second premolar. J. Endod., 18(6):271-4, 1992a.

Phillips, J. L.; Weller, R. N. \& Kulild, J. C. The mental foramen: 3. Size and position on panoramic radiographs. J. Endod., 18(8):383-6, 1992b.

Prabodra, L. B. L. \& Nanayakkara, B. G. The position, dimension and morphological variations of mental foramen in mandibles. Galle Med. J., 11:13-5, 2006.
Sawyer, D. R.; Kiely, M. L. \& Pyle, M. A. The frequency of accessory mental foramina in four ethnic groups. Arch. Oral Biol., 43(5):41720, 1998.

Schulze, R.; Schalldach, F. \& d'Hoedt, B. Effect of positioning errors on magnification factors in the mandible in digital panorama imaging. Mund. Kiefer. Gesichtschir., 4(3):164-70, 2000.

Shankland, W. E. 2nd. The position of the mental foramen in Asian Indians. J. Oral Implantol., 20(2):118-23, 1994.

Singh, R. \& Srivastav, A. K. Study of position, shape, size and incidence of mental foramen and accessory mental foramen in indian adult human skulls. Int. J. Morphol., 28(4):1141-6, 2010.

Souaga, K.; Adou, A. \& Angoh, Y. Topographical and morphological study of the mandibular foramen in black Africans from the Ivory Coast. Odontostomatol. Trop., 27(105):17-21, 2004.

Sperber, G. Craniofacial Development. London, B. C. Decker, 2001.

Sweet, A. P. S. Radiodontic study of the mental foramen. Dent. Radiogr. Photogr., 32:28-33, 1959.

Wang, T. M.; Shih, C.; Liu, J. C. \& Kuo, K. J. A clinical and anatomical study of the location of the mental foramen in adult Chinese mandibles. Acta Anat. (Basel), 126(1):29-33, 1986.

White, S. C. \& Pharoah, M. J. Oral Radiology: Principles and Interpretation. 5th ed. St. Louis, Mosby, 2004.

Williams, P. L.; Bannister, L. H.; Berry, M. M.; Collins, P.; Dyson, M.; Dussek, J. E. \& Ferguson, M. W. J. Gray's Anatomy: The Anatomical Basis of Medicine and Surgery. 38th ed. New York, Churchill Livingstone, 2000.

Woelfel, J. B. \& Scheid, R. C. Dental Anatomy: Its Relevance to Dentistry. 6th ed. New York, Lippincott, Williams and Wilkins, 2002.

Yosue, T. \& Brooks, S. L. The appearance of mental foramina on panoramic radiographs. I. Evaluation of patients. Oral Surg. Oral Med. Oral Pathol., 68(3):360-4, 1989a.

Yosue, T. \& Brooks, S. L. The appearance of mental foramina on panoramic and periapical radiographs. II. Experimental evaluation. Oral Surg. Oral Med. Oral Pathol., 68(4):488-92, 1989 b.

\section{Correspondence to:}

Firas Alsoleihat, BDS, PhD

Associate Professor

Department of Conservative Dentistry

Faculty of Dentistry

The University of Jordan

Amman 11942

JORDAN

Received: 14-10-2014

Accepted: 07-01-2015

Email: firas.alsoleihat@ju.edu.jo 